Int. J. Electrochem. Sci., 12 (2017) $4856-4866$

International Journal of

ELECTROCHEMICAL

SCIENCE

www.electrochemsci.org

\title{
Synthesis of N-doped Graphene for Simultaneous Electrochemical Detection of Lead and Copper in Water
}

\author{
Caihong Lei ${ }^{1}$, Shenghua Zhang ${ }^{2, *}$, Suping Zhao ${ }^{1}$ \\ ${ }^{1}$ Hangzhou Polytechnic, Hangzhou, Zhejiang, 311402, P.R. China \\ ${ }^{2}$ Institute of Urban Environment, Chinese Academy of Science, Fujian Xiamen, 361021, P.R. China \\ *E-mail: zhangshenghua5@yeah.net
}

doi: $10.20964 / 2017.06 .03$

Received: 11 January 2017 / Accepted: 22 March 2017 / Published: 12 May 2017

\begin{abstract}
In the study, glassy carbon electrode (GCE) modified by nitrogen doped graphene (N-GE) is employed to simultaneously determine copper \& lead in an electrochemical approach that features favorable sensitivity and speed. In comparison to original GCE, GCE modified by N-GE exhibited remarkably boosted electrochemical activity as for square wave anodic stripping voltammetry. The detection range of copper exhibited in reduced graphene oxide (RGO) modified GCE was wide from 0.05 to $2.5 \mu \mathrm{M}$, with a detection limit of $11 \mathrm{nM}$, while that of lead was from 0.05 to $2.5 \mu \mathrm{M}$ with a detection limit of 5 $\mathrm{nM}$. Besides, the proposed sensor was significantly reproducible with a desirable performance in antiinterference.
\end{abstract}

Keywords: Graphene; Doping; Electroanalysis; Heavy metal ions; Lead; Copper

\section{FULL TEXT}

(C) 2017 The Authors. Published by ESG (www.electrochemsci.org). This article is an open access article distributed under the terms and conditions of the Creative Commons Attribution license (http://creativecommons.org/licenses/by/4.0/). 